\title{
Modeling plan-form deltaic response to changes in fluvial sediment supply
}

\author{
J.H. Nienhuis ${ }^{1}$, A.D. Ashton ${ }^{2}$, P.C. Roos ${ }^{1}$, S.J.M.H. Hulscher ${ }^{1}$, L. Giosan ${ }^{2}$ \\ ${ }^{1}$ Water Engineering and Management, University of Twente, P.O. Box 17, 7500 AE Enschede. jhnienhuis@gmail.com; \\ P.C.Roos@utwente.nl; S.J.M.H.Hulscher@utwente.nl \\ ${ }^{2}$ Geology and Geophysics Department, Woods Hole Oceanographic Institution, MS \#22, 360 Woods Hole Rd., Woods Hole, MA \\ 2543, aashton@whoi.edu
}

\begin{abstract}
This study focuses on the effects of changes in fluvial sediment supply on the plan-form shape of wave-dominated deltas. We apply a one-line numerical shoreline model to calculate shoreline evolution after (I) elimination and (II) time-periodic variation of fluvial input. Model results suggest four characteristic modes of wave-dominated delta development after abandonment. The abandonment mode is determined by the pre-abandonment downdrift shoreline characteristics and wave climate (which are, in turn, determined by previous delta evolution). For asymmetrical deltas experiencing shoreline instability on the downdrift flank, time-periodic variation in fluvial input influences the evolution of downdrift-migrating sandwaves. The frequency and magnitude of the riverine "forcing" can initiate a pattern that migrates away from the river mouth, interacting with the development of shoreline sandwaves. Model results suggest that long-period signals in fluvial delivery can be shredded by autogenic sand waves, whereas shorter-term riverine fluctuations can dominate the signal of the autogenic sandwaves. The insights provided by these exploratory numerical experiments provide a set of hypotheses that can be further tested using natural examples.
\end{abstract}

\section{INTRODUCTION}

River deltas are dynamic and complex depositional landforms, shaped by marine and fluvial processes. This study aims at identifying and characterizing the long-term (centennial to millennial) response of wave-dominated river deltas to temporal changes in fluvial sediment load.

We select two scenarios: (I) fluvial input elimination and (II) periodic fluvial input variation. The first can be the result of delta channel avulsion, which causes sediment to be routed through a new channel [Roberts, 1997], or river damming [Milliman et al., 2008], which can effectively reduce sediment delivery. The Ebro Delta, Spain, is an example of a delta that has experienced both avulsions and, recently, the effects of river damming. Periodic fluvial variation can arise from cyclic climate forcing. These scenarios are studied using an 1-line numerical model of Ashton et al. [2006a].

Galloway [1975] recognized that the environmental controls of river discharge, tidal range and wave energy flux have a first-order morphologic control on delta shape. The dominance of one of these factors makes respectively a river-, tide- or wave-dominated delta. Other reported influences are grain size distribution [Orton and Reading, 1993], (relative) sea-level rise [Giosan et al., 2006], human engineering [Syvitski et al., 2009], sediment cohesion [Edmonds and Slingerland, 2010], and angular distribution of wave energy [Ashton and Giosan, 2011]. This last aspect is also the focus of this research.

The selective treatment of one physical process, only wavesustained littoral transport, makes this research applicable to wave-dominated deltas.

\section{BACKGROUND}

Waves primarily control deltaic shape through the alongshore transport of sediment by breaking waves, called the littoral drift [Komar, 1973]. Wave height and approach angle affect the amount of transport. Littoral transport in this model is calculated using the CERC formula, relating the direction and height of the breaking waves to the littoral transport [Ashton and Murray, 2006a], equation (1).

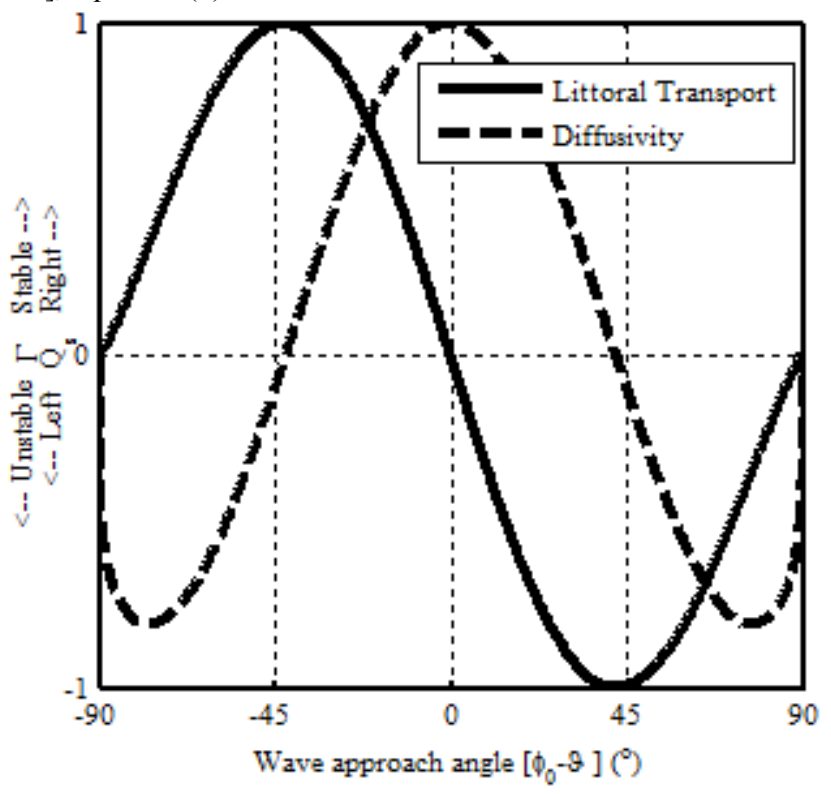

Figure 1: Alongshore sediment transport (Qs) and shoreline diffusivity $(\Gamma)$ as a function of wave approach angle (relative between the wave crests and the shoreline). 


$$
Q_{S}=K \cdot H_{b^{\frac{5}{2}}} \cdot \cos \left(\varphi_{b}-\vartheta\right) \cdot \sin \left(\varphi_{b}-\vartheta\right)
$$

$K$ is an empirical constant, which can vary greatly between different sediment types. $K$ is set to 0.34 for all runs. $H_{\mathrm{b}}$ is the breaking wave height. $\varphi_{\mathrm{b}}-\vartheta$ is the difference between the crests of incoming waves $\left(\varphi_{\mathrm{b}}\right)$ and the shoreline orientation $(\vartheta)$.

Figure 1 shows the relation between wave approach angle and littoral transport. Transport is zero when waves approach normal to the shore, $\varphi_{\mathrm{b}}-\vartheta$ equals $0^{\circ}$. Maximum transport occurs when deep water waves approach the toe of the shoreface at about $42^{\circ}$.

Appling the Exner equation of sediment continuity along the shoreline gives:

$$
D \cdot \frac{\partial \eta}{\partial t}+\frac{\partial Q_{S}}{\partial x}=f(x, t)
$$

Here, the alongshore derivative in littoral transport $\frac{\partial Q_{S}}{\partial x}\left(\mathrm{~m}^{2} \mathrm{~s}^{-1}\right)$ equals accretion or erosion $\frac{\partial \eta}{\partial t}\left(\mathrm{~ms}^{-1}\right)$ up to the local closure depth $\overline{\partial t}$

$D(\mathrm{~m})$, set at $10 \mathrm{~m}$. The physical interpretation of this equation, with $D$ constant and one description for the shoreline position $\eta$, is that cross-shore dynamics can be superimposed on alongshore behaviour, such that one typical cross-shore profile suffices to describe long-term coastal change. Assuming that sandy, bed-load sediment remains confined close to the shore, erosion or accretion of the shore is proportional to the divergence of this transport [Ashton and Murray, 2006a]. The source term $f(x, t) \quad\left(\mathrm{m}^{2} \mathrm{~s}^{-1}\right)$ represents the coarse-grained fluvial sediment kept in the nearshore zone.

The combination of equation (1) and (2) leads to a diffusion equation. The diffusion coefficient, $\Gamma$, figure 1 , controls the rate that approaching waves can cause plan-view shoreline perturbations to decrease (stable shoreline, $\Gamma>0$ ) or increase (unstable shoreline, $\Gamma<0$ ) [Ashton and Murray, 2006b].

Previous model results suggest that, as downdrift shorelines experience higher angle waves, they have an increased probability of spit formation and shoreline instability [Ashton and Giosan, 2011]. Higher waves increase littoral transport away from the delta, thus decreasing the plan-view cross-shore extent (due to an increased diffusivity) [Komar, 1973].

\section{SHORELINE EVOLUTION MODEL}

The model uses the "one-contour-line" approach to calculate fluxes of sediment and subsequent shoreline orientation across computational cells. Adding "fluvial" sediment in a cell at a predefined position and time, $f(x, t)$, along the shore simulates the plan-view evolution of a wave-dominated delta [Ashton and Giosan, 2011].

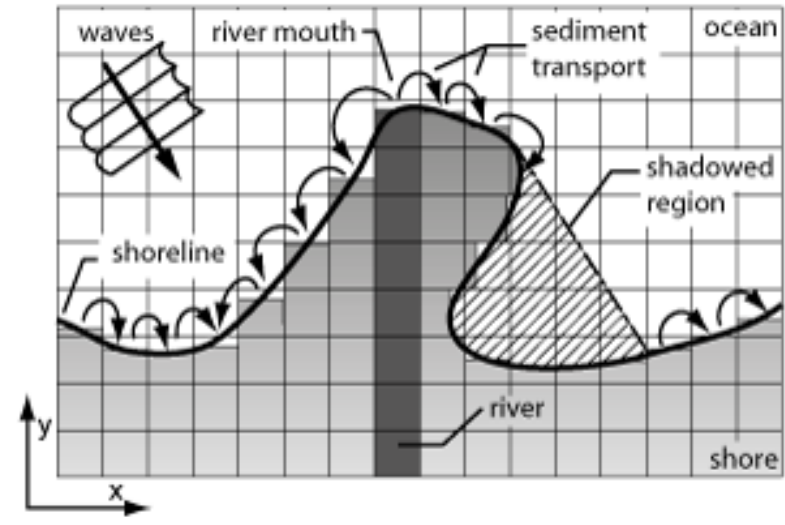

Figure 3: Schematic overview of the model domain. Wave and shoreline orientation determine fluxes between cells, which can be shadowed from other cells. (After Ashton and Murray 2006a)
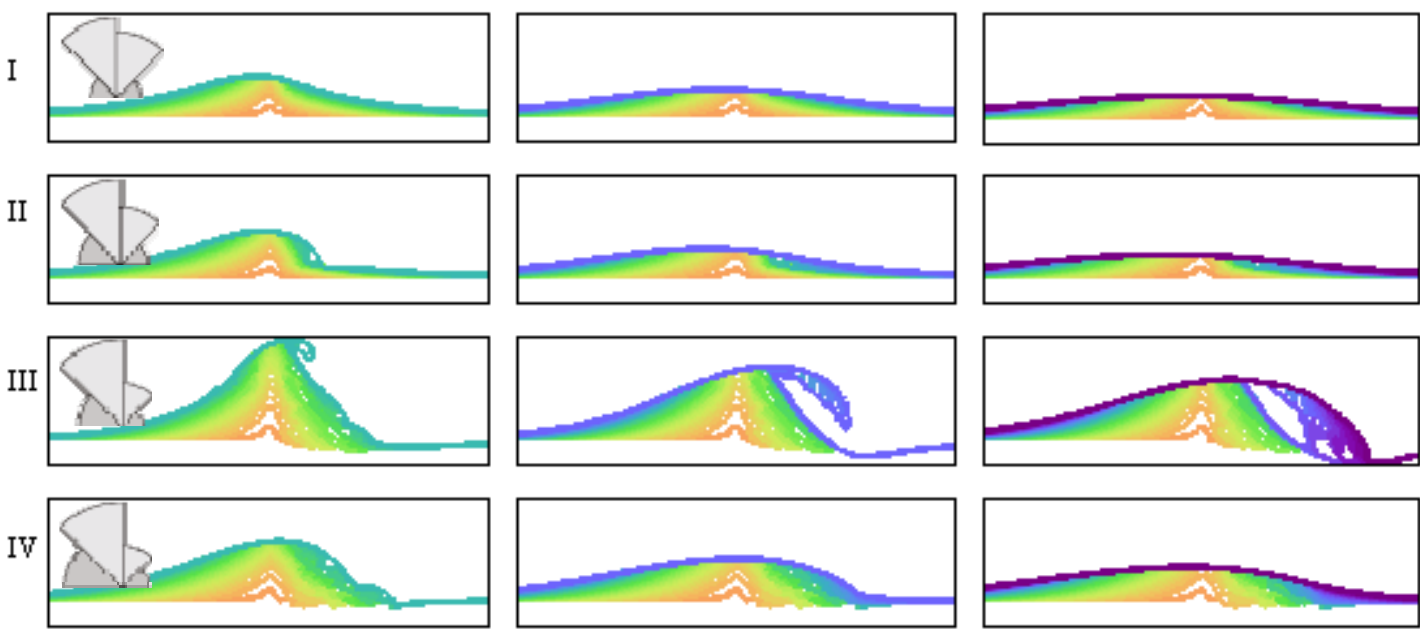

Time: 550 years

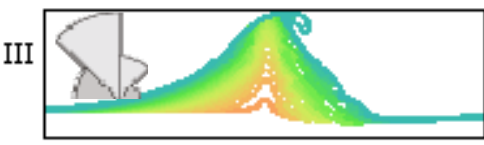

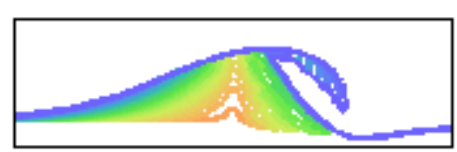

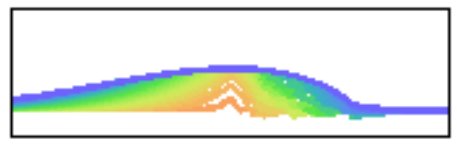

Time: 750 years
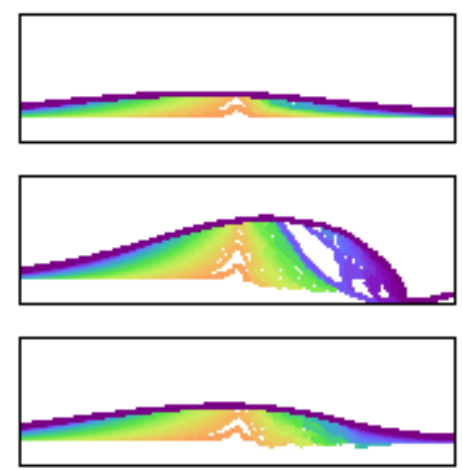

Time: 950 years

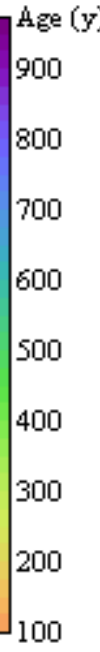

Figure 2: Examples of the four identified modes of lobe abandonment. Lines show the shoreline position, colored according to the time of deposition. Abandonment occurs after 500 years; three snapshots show delta buildup 50, 250 and 450 years after elimination of fluvial sediment supply (at time = 500 years). (I) Diffusive Mode; (II) Discontinuous Mode; (III) Spit Mode; (IV) Sandwave Mode. The wave-rose insets show the angular distribution of wave energy that is used throughout the simulations. NB. All other parameters are left constant between these runs. (fluvial bedload: $100 \mathrm{kgs}^{-1}$; deep water waveheight (1m); wave period (8s)) 
The plan-view coastal zone is discretized (Figure 3) into $200 \mathrm{~m}$ square cells. A fractional value $F$ describes the portion of subaerial surface of each cell, being between 0 and 1 if the cell is part of a shoreline. If $F$ equals 1 , the cell consists entirely of "land". The algorithm uses $F$ to trace the location and orientation of the shore within a cell. Shore location is a fraction of the cell length perpendicular to the subaerial neighbour. The position of the adjoining shores determines the orientation.

Each time step, set at 1 day, a wave direction is picked from a probability distribution. Wave height is set constant in the simulations. These waves then determine the amount of sediment transport across neighbouring shoreline cells, using equation (1).

\section{RESULTS I: ABANDONMENT BEHAVIOUR}

Model runs show four characteristic morphologic scenarios that can develop when deltas are cut off from their sediment supply: (I) diffusive mode, (II) discontinuous mode), (III) spit mode and (IV) a (shoreline) sandwave mode (Figure 2).

The 'diffusive' mode occurs when the initial delta has a classic cuspate shape, and both updrift and downdrift shoreline are stable. The delta shape is flattened by alongshore transport gradients, with erosion around the river mouth, and deposition further away.

The 'discontinuous' mode arises when the downdrift delta shore is near the limit of instability, $\Gamma$ is close to 0 . There is a discontinuity in the shoreline orientation where $\Gamma$ becomes positive. This discontinuity migrates downdrift, eroding parts of the delta. Infilling of these sections by younger sediments occurs, but flattening of the shoreline happens rapidly, such that it does not result in the formation of a spit.

When a larger downdrift section is unstable $(\Gamma<0)$, a spit grows that migrates away from the old river mouth. The steeper downdrift shoreline causes spits to shadow and erode deltaic and non-deltaic sediments.

Finally, highly unstable wave climates trigger the formation of shoreline sandwaves (IV) on the downdrift delta even before abandonment. Increased sediment transport away from the river mouth decreases the overall plan-view extent. Abandonment creates a spit that collapses near the river mouth. The influence of the delta geometry before abandonment on the future evolution is demonstrated by plotting two characteristics of the downdrift shoreline, that extends from the river mouth to the delta foot: diffusivity $(\Gamma)$ and steepness $\left(\tan ^{-1}\left(\frac{y}{x}\right),{ }^{\circ}\right)$ (Figure 4). A steep downdrift shoreline, which is unstable at the current wave conditions, generates a spit.

Along the Mediterranean coast, several deltas show morphologic features that can be placed in this framework. The Ebro delta, Spain, provides a remarkable example of where reworking of lobes has caused the growth of spits [Canicio and Ibanez, 1999]. There is also lobe reworking at the Rhone delta, France [Vella et al., 2005], suggesting evidences of a growing discontinuity and a spit. Diffusive reworking seems to take place at the Ombrone River, Italy [Pranzini, 2001].

\section{RESULTS II: PERIODIC INPUT VARIATION}

Periodic variations in sediment load have several interesting consequences for delta development, particularly when the downdrift coast is experiencing unstable wave conditions. We will

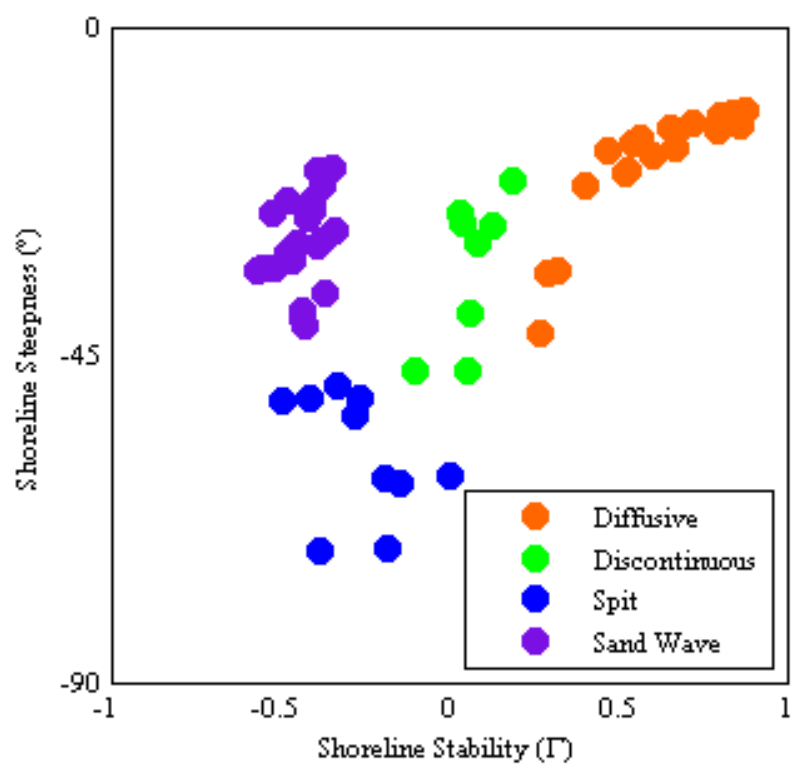

Figure 4: The abandonment framework plots the four visually characterized modes dependent on downdrift shoreline stability (or: net diffusivity) and steepness. Different wave heights $(0.8 / 0.9 / 1.0 \mathrm{~m})$, fluvial input $\left(80,100,120 \mathrm{kgs}^{-1}\right)$ and wave climates are used to generate these results.

discuss the effects on downdrift-extending shoreline sandwaves and general delta stratigraphy.

Sandwaves grow when a large portion of the shoreline is unstable (i.e. experiencing predominantly high-angle waves). The frequency and size of these autogenic features depends on wave climate and beach characteristics [Ashton and Murray, 2006a]. Sandwaves can also develop allogenically (that is, forced externally), as the river mouth location oscillates between periods of high and low fluvial sediment input.

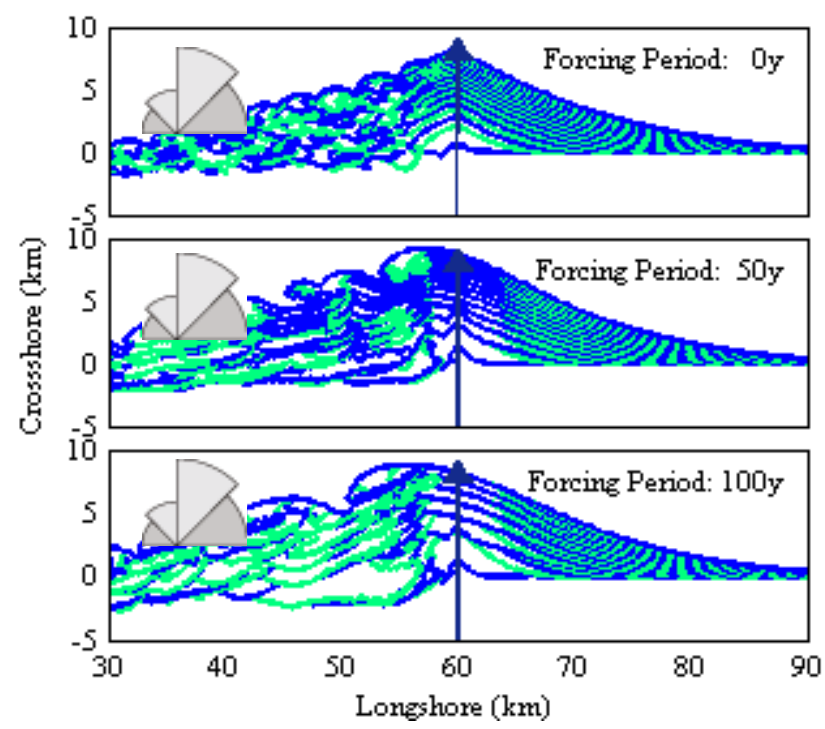

Figure 5: Downdrift (30-60km) and updrift $(60-90 \mathrm{~km})$ shoreline locations drawn with a 50 year interval for different periods of onoff fluvial variability, $50 \%$ in this case (i.e. 150-50-150 $\mathrm{kgs}^{-1}$ ). The wave-rose insets plot the angular distribution of wave energy. 


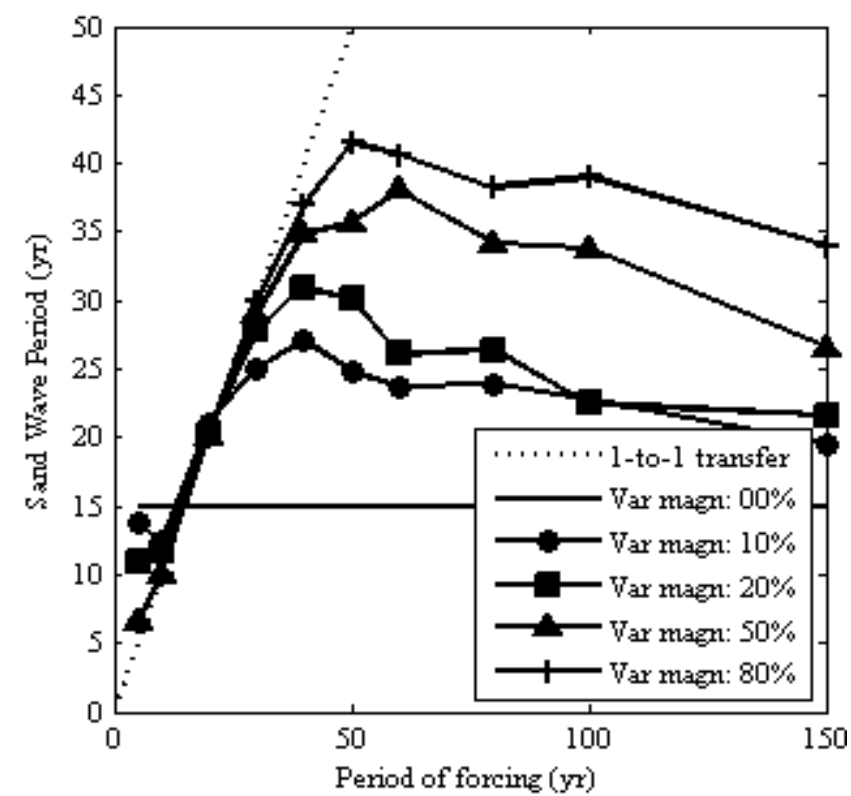

Figure 6: Period of forcing (fluvial sediment load) compared to the measured period of downdrift shoreline sand waves. The percentages indicate the amount of fluctuation (e.g. $50 \%$ is: 150 50-150 etc).

Longer forcing periods change the shape of downdrift features, leaving a distinct imprint in the plan-view deltaic stratigraphy, figure 5 .

We looked at the generation of these (allogenic) sandwaves in relation with (autogenic) sandwaves that form at the unstable downdrift shoreline (Figure 6). There is a 1-to-1 transfer of frequencies when the forcing period is close to the autogenic period, 15 years in this case. Above and below this period of forcing, different frequency sandwaves interact. The amount of variation and the frequency both determine if a signal can be preserved. These preliminary numerical experiments suggest potential detection limits of climate patterns in marine stratigraphy.

\section{CONCLUSION}

Shoreline simulations with different fluvial scenarios provide a series of hypotheses that can be further tested through comparison with natural examples. Features modeled and shown in this paper all arise from one feedback inherent in alongshore littoral transport. Other natural processes can and will change the frameworks and other findings presented here.

We identify four distinct modes in which lobe abandonment can take place. The shoreline shape and wave climate determine how littoral transport reworks the plan-view delta. Going from high to low downdrift instability, abandonment can be characterized by the following modes: diffusive, discontinuity, a spit, or sand waves. These features form primarily during the abandonment phase of the delta.

Time-periodic variations in sediment supply may drastically alter delta development and depositional trends. Signals in sediment input can force their frequency on downdrift autogenic instability. Due to differences in sand wave celerity, selforganization can potentially shred a climate signal. Sediment variability results in concave beach ridges updrift and lagoon formation in downdrift deposits.

Changes in riverine sediment input rework a deltaic shoreline. Several feedbacks between the shoreline and its reworking wave climate create a wide range of potential developments. Understanding these conditions helps determine the style and results of historical, current and future delta evolution. Research is needed to provide further comparison with natural systems.

\section{REFERENCES}

Ashton, A. D., and A. B. Murray (2006a), High-angle wave instability and emergent shoreline shapes: Modeling of sand waves, flying spits, and capes, J. Geophys. Res., 111, F04011.

Ashton, A. D., and A. B. Murray (2006b), High-angle wave instability and emergent shoreline shapes: Wave climate analysis and comparisons to nature, J. Geophys. Res., 111, F04011.

Ashton, A. D., and L. Giosan (2011), Wave-angle control of delta evolution, Geophys Res Lett, 38, L13405.

Canicio, A., and C. Ibanez (1999), The Holocene Evolution of the Ebro Delta Calalonia, Spain, Acta Geographica Sinica, 54(5), 462-469.

Edmonds, D. A., and R. L. Slingerland (2010), Significant effect of sediment cohesion on delta morphology, Nature Geoscience, 3(2), 105-109.

Galloway, W. D. (1975), Process Framework for describing the morphologic and stratigraphic evolution of deltaic depositional systems, in Deltas Models for Exploration, edited, pp. 87-89.

Giosan, L., J. P. Donnelly, S. Constantinescu, F. Filip, I. Ovejanu, A. Vespremeanu-Stroe, E. Vespremeanu, and G. A. T. Duller (2006), Young Danube delta documents stable Black Sea level since the middle Holocene: Morphodynamic, paleogeographic, and archaeological implications, Geology, 34(9), 757-760.

Komar, P. D. (1973), Computer models of delta growth due to sediment input from rivers and longshore transport, GSA Bulletin, 84(7), 2217-2226.

Milliman, J. D., K. L. Farnsworth, P. D. Jones, K. H. Xu, and L. C. Smith (2008), Climatic and anthropogenic factors affecting river discharge to the global ocean, 1951-2000, Global and Planetary Change, 62(3-4), 187-194.

Orton, G. J., and H. G. Reading (1993), Variability of deltaic processes in terms of sediment supply, with particular emphasis on grain size, Sedimentology, 40(3), 475-512.

Pranzini, E. (2001), Updrift river mouth migration on cuspate deltas: two examples from the coast of Tuscany (Italy), Geomorphology, 38(1-2), 125-132.

Roberts, H. H. (1997), Dynamic changes of the Holocene Mississippi River delta plain: The delta cycle, Journal of Coastal Research, 13(3), 605-627.

Syvitski, J. P. M., et al. (2009), Sinking deltas due to human activities, Nature Geoscience, 2(10).

Vella, C., T.-J. Fleury, G. Raccasi, M. Provansal, F. Sabatier, and M. Bourcier (2005), Evolution of the Rhone delta plain in the Holocene, Marine geology, 222-223, 235-265. 